\title{
VALIDATED CHIRAL LC METHOD FOR DEXRABEPRAZOLE ON REVERSE PHASE AMYLOSE BASED STATIONARY PHASE
}

\author{
KIRAN R. PATIL ${ }^{1,2}$, VIPUL P. RANE ${ }^{1,2}$, RAVINDRA D. YEOLE ${ }^{2}$, JAIPRAKASH N. SANGSHETTI ${ }^{1}$, \\ DEVANAND B. SHINDE *I
}

\author{
${ }^{I}$ Department of Chemical Technology, Dr. Babasaheb Ambedkar Marathwada University, Aurangabad- 431004 (MS), India; \\ ${ }^{2}$ Wockhardt Research Centre, Aurangabad-431210 (MS), India \\ (Received: December 12, 2010 - Accepted: March 21, 2011)
}

\begin{abstract}
A simple, rapid and robust LC method was developed and validated for the enantiomeric separation of dexrabeprazole in bulk drug and formulation. The enantiomers of dexrabeprazole were resolved on a Chiralpak AD-RH (amylose based stationary phase) column using a mobile phase consisting of water: acetonitrile $(50: 50, v / v)$ at a flow rate of $0.5 \mathrm{ml} \mathrm{min}^{-1}$. The resolution between the enantiomers was found to be more than 1.5 in optimized method. The developed method was extensively validated and proved to be robust. The calibration curve for (S)-enantiomer showed excellent linearity over the concentration range of 0.05 $\mu \mathrm{g} \mathrm{ml}^{-1}$ (LOQ) to $1 \mu \mathrm{g} \mathrm{ml}^{-1}$. The limit of detection and limit of quantification for (S)-enantiomer were $0.015 \mu \mathrm{g} \mathrm{ml}^{-1}$ and $0.05 \mu \mathrm{g} \mathrm{ml}{ }^{-1}$, respectively. The percentage recovery of the (S)-enantiomer ranged between 97 to $101 \%$ in bulk drug samples of dexrabeprazole. The proposed method was found to be suitable and accurate for quantitative determination of (S)-enantiomer in bulk drug substance.
\end{abstract}

Keywords: Dexrabeprazole, Chiral HPLC, Enantiomer, Validation

\section{INTRODUCTION}

Rabeprazole (Fig. 1a) 2-[[[4-(3-Methoxypropoxy)-3-methyl-2-pyridinyl] methyl]sulfinyl]- $1 H$-benzimidazole is a proton pump inhibitor that inhibits gastric acid secretion via interaction with $\left(\mathrm{H}^{+} / \mathrm{K}^{+}\right)$-ATPase in gastric parietal cells ${ }^{1-3}$. This drug contains asymmetric sulfur in its chemical structure and is clinically administered as a racemic mixture of $R$ and $S$ enantiomers (Fig. $1 \mathrm{~b}$ and $1 \mathrm{c}$ respectively). Dexrabeprazole $[(R)(+)$ rabeprazole $]$ is a novel proton pump inhibitor, which has recently become available in India for the treatment of acid peptic diseases. Experimental and clinical studies have shown superiority of dexrabeprazole (at half the recommended rabeprazole dose) over rabeprazole in terms of favorable pharmacokinetics, better efficacy and faster healing activity. Dexrabeprazole showed its effectiveness in the treatment of gastro-oesophageal reflux disease and also showed its effectiveness in the treatment of patients with peptic ulcers (gastric/duodenal) ${ }^{4}$. Owing to the pharmacological difference between these enantiomers, it is quite important to develop an enantio specific LC method for quality assurance of drug substance and drug product.

Separation of enantiomers has become very important in analytical chemistry, especially in the pharmaceutical and biological fields, because some stereoisomer of racemic drugs have quite different pharmacokinetics and different pharmacological or toxicological effects ${ }^{5}$.

It was revealed from the literature survey, that the chiral high-performance liquid chromatography method for enantiomeric separation of rabeprazole by using Chiralpak AD-H [tris(3,5 dimethylphenyl carbamate) amylose] column in normal phase mode ${ }^{6}$ and determination of rabeprazole enantiomers and their metabolites by HPLC and solid phase extraction ${ }^{7}$ were reported.

In the present investigation, we report the development and validation of a reverse-phase LC method using polysaccharide amylose based stationary phase (Chiralpak AD-RH) column for determination of enantiomeric purity of dexrabeprazole in bulk drugs and in pharmaceutical dosage form. We developed a rapid method with short time analysis and cost effective. The main advantages of developed method are the method is reverse phase and useful for preparative HPLC separation and routine analysis in quality control labs due to short run time and better resolution. The developed method was validated with respective linearity, accuracy, precision, LOD, LOQ and robustness.<smiles>COCCCOc1ccnc(CS(=O)(=O)c2nc3ccccc3[nH]2)c1C</smiles>

1a<smiles>COCCCOc1ccnc(C[S@](C)(=O)c2nc3ccccc3n2[13CH3])c1C</smiles>

$1 \mathrm{~b}$<smiles>COCCCOc1ccnc(C[SH](C)(=O)c2nc3ccccc3n2[13CH2])c1C</smiles>

$1 \mathrm{c}$

Fig 1. Chemical Structure of Rabeprazole (1a), Dexrabeprazole ( $R$-Rabeprazole, $1 \mathrm{~b})$ and Levorabeprazole ( $S$-Rabeprazole, $1 \mathrm{c})$.

\section{EXPERIMENTAL}

Chemicals and Equipments

Sample of $(S)$-enantiomer and dexrabeprazole were obtained from Emcure Pharmaceuticals Limited (Pune, India). Dexrabeprazole formulation tablets (Dexpure $5 \mathrm{mg}$ ) purchased from local medical shop. HPLC grade acetonitrile was purchased from Rankem Fine chemical (Mumbai, India). Double distilled water was used throughout the experiment.

HPLC system used was an Agilent Technology (1100 series, Germany), system equipped with auto sampler, quaternary pump, degasser and a UV 
Detector. The out put signal was monitored and processed using Agilent Chemstation software.

\section{Sample Preparation}

The stock solution of $(R)$-enantiomer i.e. dexrabeprazole $\left(1.0 \mathrm{mg} \mathrm{ml}^{-1}\right)$ was prepared by dissolving appropriate amount of substance in mobile phase. For quantification of $(S)$-enantiomer in dexrabeprazole, a solution of $50 \mu \mathrm{g} \mathrm{ml}^{-1}$ concentration was used.

\section{Chromatographic condition}

The chromatographic column used was $150 \times 4.6 \mathrm{~mm}$ ChiralPak AD-RH (Daicel Chemical Industries, Ltd., Tokyo, Japan) packed with $5 \mathrm{~mm}$ particles. The mobile phase was water: acetonitrile $(50: 50, v / v)$. The flow rate of the mobile phase was $0.5 \mu 1 \mathrm{~min}^{-1}$. The column temperature was maintained at $40^{\circ} \mathrm{C}$ and the eluent was monitored at a wavelength of $284 \mathrm{~nm}$. The injection volume was $2 \mu 1$.

System suitability

The System suitability was determined by injecting racemic mixture containing equal quantity of $(S)$-enantiomer and dexrabeprazole. The qualification criteria was resolution between two enantiomers, shown to be not less than 1.5 and tailing factor should not exceed 1.5.

Precision

Method reproducibility was determined by measuring repeatability and intermediate precision (between-day precision) of retention times and peak areas for each enantiomer. In order to determine the repeatability of the method, replicate injections $(\mathrm{n}=6)$ of $50 \mu \mathrm{g} \mathrm{ml}^{-1}$ solution containing dexrabeprazole spiked with $(S)$-enantiomer $(1 \%)$ was carried out. The intermediate precision was also evaluated by performing six successive injections by another analyst.

Linearity of $(S)$ - enantiomer

Linearity was assessed by preparing six calibration sample solutions of $(S)$-enantiomer covering from $0.05 \mu \mathrm{g} \mathrm{ml}^{-1}$ (LOQ) to $1 \mu \mathrm{g} \mathrm{ml}^{-1}(0.05,0.1,0.25$, $0.4,0.5$ and $1 \mu \mathrm{g} \mathrm{ml}^{-1}$ ), prepared in mobile phase from $(S)$ - enantiomer stock solution.

The regression curve was obtained by plotting peak area versus concentration, using the least squares method. The percentage relative standard deviation of the slope and Y-intercept of the calibration curve was calculated.

Quantification of $(S)$-enantiomer in bulk sample and formulation

The Dexrabeprazole bulk sample did not show the presence of $(S)$ enantiomer. Standard addition and recovery experiment were conducted to determine the accuracy of the present method for the quantification of $(S)$ enantiomer in bulk drug samples.

The study was carried out in triplicate at 50,100 and $150 \%$ of the $(S)$ enantiomer target analyte concentration. The recovery of $(S)$-enantiomer was calculated from the slope and Y-intercept of the calibration curve

Dexpure tablets containing $5 \mathrm{mg}$ Dexrabeprazole. Ten tablets of Dexpure $(5 \mathrm{mg})$ were finely ground using agate mortar and pestle. The ground material, which was equivalent to $5 \mathrm{mg}$ of the active pharmaceutical ingredient (Dexrabeprazole), was dissolved into mobile phase in $100 \mathrm{ml}$ volumetric flask by vortex mixing followed by ultrasonication. The resultant mixture was filtered through $0.45-\mu \mathrm{m}$-membrane filter. The filtrate was used as solution for preparing the accuracy test solutions. This solution corresponds to analyte concentration of $50 \mu \mathrm{g} \mathrm{ml}^{-1}$.

Limit of detection and Limit of quantification of $(S)$-enantiomer (LOD \& LOQ)

Limit of detection and limit of quantification of $(S)$-enantiomer were achieved by injecting a series of dilute solutions of $(S)$-enantiomer ${ }^{8}$. The precision of the developed enantioselective method for $(S)$-enantiomer at limit of quantification was checked by analyzing six test solutions prepared at LOQ level and calculating the percentage relative standard deviation of area.

\section{Robustness}

The flow rate of the mobile phase was $0.5 \mathrm{ml} \mathrm{min}^{-1}$. To study the effect of flow rate on resolution of enantiomers, it was changed 0.1 units from 0.4 to $0.6 \mathrm{ml} \mathrm{min}{ }^{-1}$ while the other mobile phase components were held constant. The effect of change in percent of acetonitrile on resolution was studied by varying from -1 to $+1 \%$ while the other mobile phase components were held constant. The effect of column temperature on resolution was studied at $38^{\circ} \mathrm{C}$ and $42^{\circ} \mathrm{C}$ instead of $40^{\circ} \mathrm{C}$ while other mobile phase components were held constant, as stated in chromatographic condition section.

\section{Solution stability and mobile phase stability}

Stability of dexrabeprazole in solution at analyte concentration was studied by keeping the solution in tightly capped volumetric flask at room temperature on laboratory bench for 1 day. Content of $(S)$-enantiomer was checked at $6 \mathrm{hr}$ intervals up to the study period.

\section{RESULT AND DISCUSSION}

To develop the suitable chiral HPLC method for the separation of the enantiomers of rabeprazole, different mobile phases were employed. There was an indication of separation on Chiralpak AD-RH column using the mobile phase consisting of water: acetonitrile $(70: 30, v / v)$ but the peak shape was broad. For further improvement in resolution, peak shape and column efficiency, the acetonitrile proportion was increased. Better separation was achieved on Chiralpak AD-RH column (resolution between enantiomers was found to be $>1.5)$ using the mobile phase water: acetonitrile $(50: 50, v / v)$, which produces better resolution and chromatographic analysis time less than $10 \mathrm{~min}$.

The mechanism of chiral separation methods is the interaction of chiral stationary phase (CSP) with analytes to form short-lived, transient diastereomeric complexes. The complexes are formed as a result of hydrogen bonding, dipole-dipole interactions, $\pi$ bonding, electrostatic interactions, and inclusion complexation ${ }^{9-10}$. The electronegative atoms such as nitrogen and oxygen along with the aromatic rings of rabeprazole might participate in hydrogen bonding and dipole-dipole induced interactions with - $\mathrm{CO}-$ and $-\mathrm{NH}-$ groups of carbamate moieties of amylase derived stationary phase. Furthermore there could be $\pi-\pi$ interactions of different magnitudes between the substituted phenyl moieties of carbamate and the aromatic rings of rabeprazole enantiomer. A representative chromatogram of rabeprazole enantiomers is shown in Fig.2a, showing an excellent resolution $\left(\mathrm{R}_{\mathrm{s}}=1.8\right)$ between two enantiomers and symmetric peak shape with tailing 1.2 was obtained. In the optimized method, the typical retention time of dexrabeprazole and $(S)$-enantiomer were about 6.7 and $7.5 \mathrm{~min}$, respectively. The system suitability test results of the chiral liquid chromatographic method on Chiralpak AD-RH are presented in Table 1.

Table 1. System suitability report.

\begin{tabular}{|lllllc|}
\hline Enantiomers & $\mathrm{R}_{\mathrm{t}}(\min )$ & $\alpha$ & $\mathrm{Rs}$ & $\mathrm{N}$ & $\mathrm{T}$ \\
\hline$(R)$-enantiomer & 6.78 & 1.11 & - & 3588 & 1.2 \\
$(S)$-enantiomer & 7.55 & - & 1.8 & 2827 & 1.1 \\
& & & & & \\
\hline
\end{tabular}

$\mathrm{n}=3, \mathrm{R}_{\mathrm{t}}$ - retention time, a - enantioselectivity, Rs - USP resolution, $\mathrm{N}$ -number of theoretical plates (USP tangent method) and T - USP tailing factor
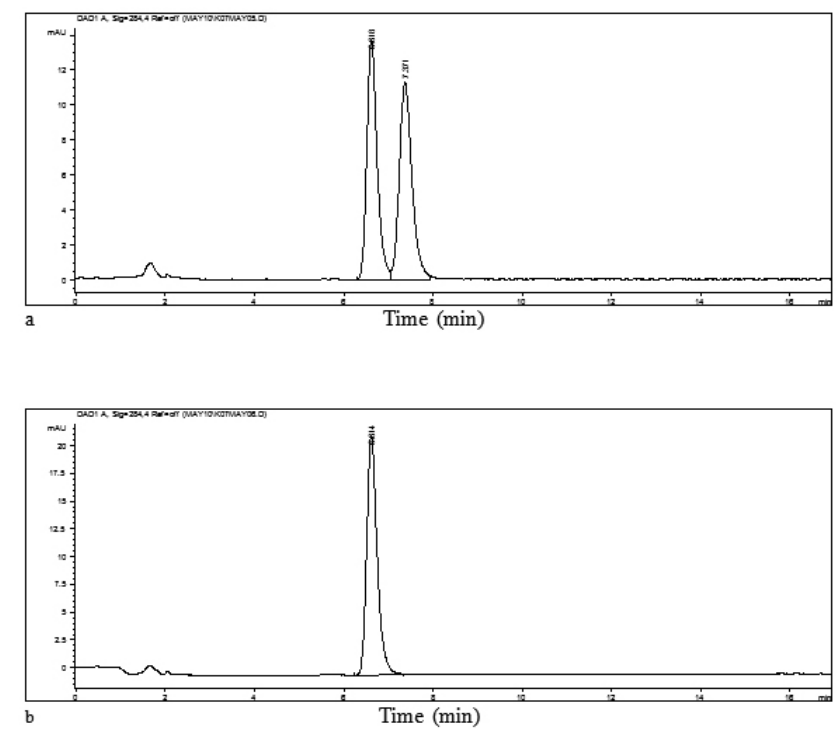

Fig 2. Chromatograph a) Enantiomeric resolution of Rabeprazole on Chiralpak AD-RH column. b) Typical HPLC chromatogram of Dexrabeprazole bulk sample $\left(50 \mu \mathrm{g} \mathrm{ml}^{-1}\right)$.

In the precision study, the percentage relative standard deviation (R.S.D.) was less than $0.1 \%$ and $0.2 \%$ for the retention times of the dexrabeprazole and (S)-enantiomer respectively. Peak area (R.S.D.) $0.15 \%$ for dexrabeprazole and $0.65 \%$ for $(S)$-enantiomer (Table 2). In the intermediate precision study, the results showed that R.S.D. values were in the same order of magnitude than those obtained for repeatability (Table 2). 
Table 2. Validation results of the developed liquid chromatographic method.

\begin{tabular}{|c|c|}
\hline Validation parameter & Results \\
\hline \multicolumn{2}{|l|}{ Repeatability ( $\mathrm{n}=6, \%$ R.S.D.) } \\
\hline Retention time ( $R$-enantiomer) & 0.03 \\
\hline Retention time (S-enantiomer) & 0.17 \\
\hline Peak area ( $R$-enantiomer) & 0.15 \\
\hline Peak area (S-enantiomer) & 0.65 \\
\hline \multicolumn{2}{|l|}{ Intermediate precision ( $n=6, \%$ R.S.D.) } \\
\hline Retention time ( $R$-enantiomer) & 0.06 \\
\hline Retention time (S-enantiomer) & 0.15 \\
\hline Peak area ( $R$-enantiomer) & 0.18 \\
\hline Peak area (S-enantiomer) & 0.55 \\
\hline \multicolumn{2}{|l|}{ LOD-LOQ (S-enantiomer) } \\
\hline Limit of detection $\left(\mu \mathrm{g} \mathrm{ml}^{-1}\right)$ & 0.015 \\
\hline Limit of detection $\left(\mu \mathrm{g} \mathrm{ml}^{-1}\right)$ & 0.05 \\
\hline Precision at LOQ (\%R.S.D.) & 1.4 \\
\hline \multicolumn{2}{|l|}{ Limearity (S-enantiomer) } \\
\hline Calibration range $\left(\mu \mathrm{g} \mathrm{ml}^{-1}\right)$ & $0.05-1$ \\
\hline Calibration points & 6 \\
\hline Correlation coefficient & 0.999 \\
\hline
\end{tabular}

The limit of detection (LOD) and limit of quantification (LOQ) concentrations were estimated to be 0.015 and $0.05 \mu \mathrm{g} \mathrm{ml}^{-1}$ for $(S)$-enantiomer, when signal-to-noise ratio of 3 and 10 were used as the criteria. The method precision for $(S)$-enantiomer at limit of quantification was less than $1.5 \%$ R.S.D. (Table 2).

The described method was linear in the range of $0.05-1 \mu \mathrm{g} \mathrm{ml}^{-1}$ for (S)enantiomer in dexrabeprazole. The calibration curve was drawn by plotting the peak area of (S)-enantiomer versus its corresponding concentration with correlation coefficient of 0.999 . The equation of the calibration curve for (S)enantiomer was $\mathrm{Y}=19.103 \mathrm{x}-0.1149$.

Recovery was calculated from slope and Y-intercept of the calibration curve, obtained in linearity study and percentage recovery ranged from 97 to $102 \%$ (Table 3). A HPLC chromatogram of dexrabeprazole sample was shown in Fig. $2 b$.
Table 3. Recovery results of (S)-enantiomer in commercial formulations.

\begin{tabular}{|llll|}
\hline Amount spiked $(\mu \mathrm{g})$ & Amount found & Recovery (\%) & \%RSD \\
\hline 0.40 & 0.39 & 97.5 & 1.05 \\
0.50 & 0.50 & 100 & 0.55 \\
0.60 & 0.61 & 101.67 & 0.49 \\
\hline
\end{tabular}

The resolution between dexrabeprazole and $(S)$-enantiomer was greater than 1,5 and enantioselectivity (a) was better under all separation conditions tested, demonstrating sufficient robustness. As flow rate of mobile phase and column temperature is increased the resolution decreased to (1.68) and enantioselectivity was not affected (1.11). The increased percentage of acetonitrile in mobile phase decreased the resolution (1.7) and selectivity also decreased to (1.05).

The \% R.S.D. of dexrabeprazole content during solution stability and mobile phase stability experiments was within $1.1 \%$. Hence dexrabeprazole sample solution and mobile phase were stable for at least $24 \mathrm{hrs}$.

\section{CONCLUSION}

A simple, rapid and reverse phase chiral HPLC method has been developed and validated for the enantiomeric separation of dexrabeprazole. The method was completely validated with respect to accuracy, precision, linearity, LOD, LOQ and robustness as per ICH guidelines. The developed method can be conveniently used by the quality control department for the quantitative determination of chiral impurity $(S)$-enantiomer in the bulk drug substance.

\section{ACKNOWLEDGEMENT}

The authors are grateful to the Head-Department of chemical technology, Dr. Babasaheb Ambedkar Marathwada University, Aurangabad, India for gift sample and providing laboratory facility for this research work.

\section{REFERENCES}

1. H. Fujisaki, K. Shibata, K. Oketani, M. Murakami, M. Fujimoto, T. Wakabayashi, I. Yamatsu, M. Yamaguchi, H. Sakai, N. Takeguchi, Biochem. Pharmacol, 42, 321 (1991).

2. M. Morii, H. Takata, H. Fujisaki, N. Takeguchi, Biochem. Pharmacol, 39, 661 (1990)

3. A. Prakash, D. Faulds, Drugs, 55, 261 (1998)

4. S. Jain, J. Indian Med. Assoc, 107(2), 111 (2009)

5. C. J. Sahajwalla, New Drug Development:Regulatory paradigms for clinical Pharmacology and Biopharmaceutics, 141, Marcel Dekker Inc., New York, 141, 421 (2004)

6. R. Nageswar, A. Narasa raju, D. Nagaraju Talanta, 70, 805 (2006)

7. M. Masatoma, T. Hitoshi, S. Shigeru, H. Tomonori, S. Toshio, J.Pharm. Biomed Anal, 41, 565 (2006)

8. Validation of analytical procedures: Text and Methodology. In ICH Harmonized Tripartite Guidelines Q2 (R1), November (2005)

9. Y. Okamoto, Y. Kaida, J. Chromatogr. A, 666, 403 (1994)

10. Y. Okamoto, E. Yashima, Angew. Chem. Int. Ed, 37, 1020 (1998). 